\title{
Interaction between postoperative shivering and hyperalgesia caused by high-dose remifentanil
}

\author{
Yoon-Kang Song ${ }^{1}$, Cheol Lee ${ }^{1}$, Dong-Hyuk Seo ${ }^{1}$, Seong-Nam Park ${ }^{2}$, Seo-Young Moon ${ }^{3}$, and \\ Chang-Hyun Park ${ }^{4}$
}

Departments of ${ }^{1}$ Anesthesiology and Pain Medicine, ${ }^{2}$ Obstetrics and Gynecology, Wonkwang University College of Medicine, Iksan, Department of Anesthesiology and Pain Medicine, ${ }^{3}$ Wonkwang University Sanbon Hospital, Gunpo, ${ }^{4}$ Presbyterian Medical Center, Jeonju, Korea

Background: High-dose remifentanil-based anesthesia is associated with opioid-induced hyperalgesia (OIH) and postanesthetic shivering (PAS). These effects can be prevented by $N$-methyl-d-aspartate (NMDA) receptor antagonists. This study aimed to investigate correlations between OIH and PAS caused by high-dose remifentanil and the effects of lowdose ketamine on OIH and PAS.

Methods: Seventy-five patients scheduled for single-port laparoscopic gynecologic surgery were randomly allocated into three groups, each of which received intraoperative remifentanil: group L at $0.1 \mu \mathrm{g} / \mathrm{kg} / \mathrm{min}$; group $\mathrm{H}$ at $0.3 \mu \mathrm{g} / \mathrm{kg} / \mathrm{min}$; and group HK at $0.3 \mu \mathrm{g} / \mathrm{kg} / \mathrm{min}$ plus $0.25 \mathrm{mg} / \mathrm{kg}$ ketamine just before incision, followed by a continuous infusion of $5 \mu \mathrm{g} / \mathrm{kg} / \mathrm{min}$ ketamine until skin closure.

Results: PAS, postoperative tactile pain threshold, and the extent of hyperalgesia in group $\mathrm{H}$ were significantly different $(\mathrm{P}$ $<0.05)$ than in the other two groups. PAS was significantly correlated with $\mathrm{OIH}$, including mechanically evoked pain such as postoperative tactile pain threshold $(\mathrm{r}=-0.529, \mathrm{P}=0.01)(\mathrm{r}=-0.458, \mathrm{P}=0.021)$ and the extent of hyperalgesia $(r=0.537, P=0.002)(r=0.384, P=0.031)$, respectively, in group $\mathrm{H}$ and group HK. Notably, both groups were treated with high-dose remifentanil. Tympanic membrane temperature, time to first postoperative analgesic requirement, postoperative pain scores, analgesic consumption, and cumulative patient-controlled analgesia volume containing morphine were comparable in all three groups.

Conclusions: $\mathrm{OIH}$, including the enhanced perception of pain, and PAS were both associated with high-dose remifentanil, were significantly correlated and were attenuated by a low dose of ketamine. This suggests that a common mechanism in part mediated through activation of the central glutamatergic system (e.g., NMDA receptors), underlies the two effects caused by high doses of remifentanil. (Korean J Anesthesiol 2014; 66: 44-51)

Key Words: Ketamine, Opioid-induced hyperalgesia, Postanesthetic shivering, Remifentanil.

Received: June 3, 2013. Revised: 1st, July 18, 2013; 2nd, August 14, 2013. Accepted: September 3, 2013.

Corresponding author: Cheol Lee, M.D., Department of Anesthesiology and Pain Medicine, Wonkwang University College of Medicine, 344-2, Sinyong-dong, Iksan 750-711, Korea. Tel: 82-63-859-1564, Fax: 82-63-857-5472, E-mail: ironyii@wku.ac.kr

(c) This is an open-access article distributed under the terms of the Creative Commons Attribution Non-Commercial License (http:// creativecommons.org/licenses/by-nc/3.0/), which permits unrestricted non-commercial use, distribution, and reproduction in any medium, provided the original work is properly cited. 


\section{Introduction}

Remifentanil is an ultra-short acting drug associated with a predictable and rapid recovery, which is relatively independent of the dose and duration of its infusion [1]. Although a number of studies have reported opioid-induced hyperalgesia $(\mathrm{OIH})$ and its prevention by $\mathrm{N}$-methyl-d-aspartate (NMDA) receptor antagonists [2-4], the effect of ketamine, a non-competitive NMDA receptor antagonist on remifentanil-induced hyperalgesia remains unclear [5-7].

Some studies have reported that postanesthetic shivering (PAS) is quite common with remifentanil-based general anesthesia [8-10]. Various drugs have been used to treat or prevent PAS, but an ideal treatment has not yet been found. However, it has been reported that a low prophylactic dose of ketamine can prevent PAS [11,12].

We hypothesized that OIH and PAS caused by high dose of remifentanil might share a common mechanism, because both can be prevented by ketamine, a non-competitive NMDA receptor antagonist. OIH was defined as an increase in mechanically evoked pain using a Von Frey filament (e.g., an increase in the area of hyperalgesia and a decrease in the tactile pain threshold) in addition to an increase in clinically relevant pain (e.g., time to first postoperative analgesic consumption, cumulative patientcontrolled analgesia [PCA] volume containing morphine, and analgesic consumption). This study aimed to identify correlations between OIH and PAS caused by high-dose remifentanil and the effects of low-dose ketamine on these symptoms in patients undergoing single-port laparoscopic gynecologic surgery.

\section{Materials and Methods}

After obtaining approval from the Institutional Review Board and written informed consent from each study participant, 75 adult women aged between 20 and 60 years were included in the study. Each patient was classified according to the American Society of Anesthesiologists physical status I-II and was scheduled to undergo single port-laparoscopic surgery. Patients were excluded from the study if: (1) they had received blood products; (2) they had a history of drug or alcohol abuse; (3) they suffered from psychiatric disorders, acute cardiovascular disorders or unstable hypertension, other respiratory or neuromuscular pathology, or multiple allergies; (4) they had been treated with any analgesic drug within $24 \mathrm{~h}$ before surgery; (5) they had contraindications to the self-administration of opioids (i.e., were unable to understand the PCA device); (6) they underwent prolonged surgery (more than $4 \mathrm{~h}$ ).

Patients were assigned to groups using a computer-generated random number table. All patients were informed that they had equal chances of being assigned to any one of three groups to be treated with intraoperative remifentanil (Ultiva ${ }^{\circledR}$, GlaxoSmithKline, Parma, Italy): group L at $0.1 \mu \mathrm{g} / \mathrm{kg} / \mathrm{min}$; group $\mathrm{H}$ at 0.3 $\mu \mathrm{g} / \mathrm{kg} / \mathrm{min}$; and group $\mathrm{HK}$ at $0.3 \mu \mathrm{g} / \mathrm{kg} / \mathrm{min}$ plus $0.25 \mathrm{mg} / \mathrm{kg}$ ketamine just before incision, followed by a continuous infusion of $5 \mu \mathrm{g} / \mathrm{kg} / \mathrm{min}$ ketamine until skin closure. On the day before surgery, patients were taught how to use the visual analog scale (VAS) and the PCA device. They were instructed to self-deliver analgesia at any time when they began to feel pain.

All patients were premedicated with 2-3 mg midazolam before arrival in the operating room. The patients monitored routinely to obtain pulse oximetry, automated cuffed blood pressure (BP), electrocardiogram (ECG), and end-tidal $\mathrm{CO}_{2}\left(\mathrm{ETCO}_{2}\right)$ measurements. Arterial and urinary catheters were used as needed for routine management, and patients received lactated Ringer's as a crystalloid intravenous (i.v.) solution. Tympanic temperature was measured immediately before the induction of anesthesia and again just before extubation.

The induction of anesthesia was commenced with a slow (30-60 s) i.v. bolus dose of remifentanil $(1 \mu \mathrm{g} / \mathrm{kg})$, followed by propofol (1-2 mg/kg), and tracheal intubation was facilitated with rocuronium $(0.9 \mathrm{mg} / \mathrm{kg})$ in all groups. As mentioned above, the infusion of remifentanil was fixed in all groups, and anesthesia was maintained with desflurane at an initial end-tidal concentration of 1 minimum alveolar concentration (MAC) and oxygen-medical air mixture (fraction of oxygen, 50\%). During surgery, anesthesia levels were monitored by stepwise titration of the desflurane concentration by 1 vol\%, based on hemodynamic changes and targeting a bispectral index (BIS) from 40-60. Our criterion for hemodynamic change was a systolic blood pressure that exceeded values between $\pm 20 \%$ of pre-induction values. Patients received $10 \mathrm{mg}$ i.v. bolus doses of ephedrine in cases of persistent hypotension. If heart rate decreased to less than 50 beats/min, a $0.5 \mathrm{mg}$ i.v. atropine bolus was administered intravenously.

Upon completion of the surgery, neuromuscular blockade was reversed with pyridostigmine $(0.2 \mathrm{mg} / \mathrm{kg})$ and glycopyrrolate $(0.008 \mathrm{mg} / \mathrm{kg})$ when the train-of-four (TOF) ratio had returned to $25 \%$. When BIS values reached 80 and spontaneous breathing was achieved, extubation was performed. The remifentanil infusion was discontinued once the final surgical stitch had been placed. Each patient was treated via PCA pump (Accufuser $^{\circledR}$ WooYoung Medical, Seoul, Korea) with analgesics containing morphine $(40 \mathrm{mg})$, ketorolac $(180 \mathrm{mg})$, and ramosetron $(0.6 \mathrm{mg})$ in normal saline and in a total volume of 100 $\mathrm{ml}$. This device was set to deliver a basal infusion of $2 \mathrm{ml} / \mathrm{h}$, and bolus doses of $0.5 \mathrm{ml}$ with a $15 \mathrm{~min}$ lockout time. Postoperative pain scores upon movement in the first hour after surgery were documented using the $100 \mathrm{~mm}$ linear VAS. The VAS is a straight line with the left end of the line representing no pain and the right end of the line representing the imaginable worst pain. 
Patients are asked to mark on the line where they perceive their pain to be.

Postoperative monitoring included noninvasive blood pressure, heart rate, and pulse oximetry. The ambient temperature in the postanesthesia care unit (PACU) was maintained at $24^{\circ} \mathrm{C}$. All patients in the PACU were monitored and covered with a cotton blanket. None of the patients were actively warmed and all received $4 \mathrm{~L} / \mathrm{min}$ oxygen by facemask. PAS was graded using a four-point scale [11] (Table 1). Patients who developed grade 2-3 shivering within the first hour were included in the study. If the shivering grade was $\geq 2$, PAS was treated using a forced airwarming blanket.

A trained anesthesiologist, who was not involved in this study, assessed pain and analgesic consumption. Due to the potential effect of opioids on PAS, an i.v. dose of ketorolac (15 mg) was administered if patients reported a VAS $\geq 30$ during the first hour after surgery. The time to the first postoperative analgesic requirement, postoperative pain scores (VAS) upon movement in the first hour after surgery, analgesic (ketorolac) consumption during the first hour after surgery and cumulative volume injected through the PCA pump within $24 \mathrm{~h}$ postoperatively were recorded.

The methods used to test mechanically evoked pain in this study were the same as those described in a previous report [13]. The pain threshold for mechanical punctuate stimuli was measured preoperatively using Von Frey filaments (Bioseb ${ }^{\mathrm{TM}}$, Chaville, France) and again $24 \mathrm{~h}$ after surgery on the dominant upper inner arm and peri-incisional areas. A Von Frey filament consists of 20 monofilaments, all of constant length but with a stepwise progression of diameters. According to the manufacturer, the numerical grade of the filaments (1.65-6.65) corresponds to a logarithmic function of forces equivalent to $0.008^{-}$ $300 \mathrm{~g}$. When the tip of a fiber of given length and diameter is pressed against a test area at right angles, the applied force increases as the researcher continues to advance the probe, until the fiber bends. After the fiber bends, advancing the probe further may induce more bending but does not apply more force to the test area. This makes it possible to apply reproducible forces, within a wide tolerance range, to the tested surface. The force is continuously applied for $1 \mathrm{~s}$ and then removed. Subjects are instructed to respond "yes" (i.e., contact was felt during the stimulation) or "no" (i.e., contact was not felt during the stimulation).

Table 1. Classification of Shivering

\begin{tabular}{cl}
\hline Grade & \multicolumn{1}{c}{ Clinical signs } \\
\hline 0 & No shivering \\
1 & Mild fasciculation of face or neck \\
2 & Visible tremor involving more than one muscular group \\
3 & Gross muscular activity involving the entire body \\
\hline
\end{tabular}

If the subject reports a negative answer (i.e., does not detect pressure), a filament with a larger diameter is used and applied with increasing intensity until the subject reacts. Then the pressure is immediately increased by using a larger filament. The tactile pain threshold was defined as the smallest force $\left(\mathrm{g} / \mathrm{mm}^{2}\right)$ necessary to bend a von Frey filament, which was just perceived to be painful.

The tactile pain threshold was determined with von Frey filaments on areas $2 \mathrm{~cm}$ from the umbilicus (preoperatively) or $2 \mathrm{~cm}$ from the single port incision site (postoperatively) at 4 points (horizontally and vertically).

Stimulation with a Von Frey filament (number, 6.1; force, $100 \mathrm{~g}$ ) was started outside the hyperalgesia area where no pain sensation was experienced, and was then moved toward the incision until the patient reported a distinct change in perception. The area of hyperalgesia for punctuate mechanical stimulation around the surgical incision was determined by testing along linear paths, quadrilaterally at a distance of $5 \mathrm{~cm}$ around the incision, $24 \mathrm{~h}$ after surgery. These observations were then translated to graph paper for the calculation of surface area (Fig. 1). The first point where a painful, sore, or sharper feeling was perceived was marked. If no change in sensation occurred, the stimulation was stopped $1 \mathrm{~cm}$ from the incision.

A preliminary investigation yielded hypothesized means in the area of hyperalgesia of $8.65,12.10$, and $11.10 \mathrm{~cm}^{2}$ for groups $\mathrm{L}, \mathrm{H}$, and $\mathrm{HK}$, respectively, with the standard deviation of subjects being 1.45. Thus, a sample size of 25 patients per group was needed to demonstrate a significant difference, with a power of $80 \%$ and an $\alpha$-coefficient of 0.05 . The statistical analysis was performed using SPSS ver. 18.0 (SPSS Inc., Chicago, IL,

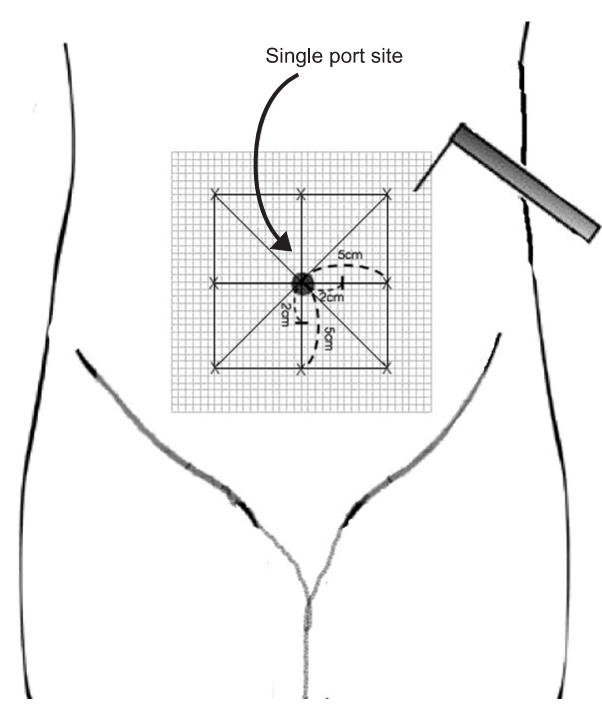

Fig. 1. Schematic representation depicting mapping of the peri-incisional area for assessment of punctuate mechanical hyperalgesia. 
USA). The results are presented as mean \pm SD or the number of patients (\%). One-way ANOVA was used for the following intergroup comparisons: age, body weight, duration of surgery and anesthesia, remifentanil dose, vol\% of desflurane, extubation time after surgery, tympanic membrane temperature, time to first postoperative analgesic requirement, postoperative pain scores upon movement in the first hour after surgery, analgesic consumption (ketorolac) during the first hour after surgery, cumulative PCA volume containing morphine within $24 \mathrm{~h}$, amount of fluid administered, and fluid irrigation. Post-hoc comparisons were performed with Bonferroni correction of the significance level. Chi-square tests were used to analyze categorical data such as PAS and the frequency of patients who received ephedrine or atropine. Correlations between PAS and postoperative tactile pain threshold, and the extent of hyperalgesia were analyzed with Kendall's tau correlation analysis. Correlations between time to first postoperative analgesic consumption, cumulative PCA volume containing morphine, analgesic consumption, tac- tile pain threshold, and extent of hyperalgesia were analyzed by Pearson correlation. $\mathrm{P}<0.05$ was considered the minimum level of statistical significance.

\section{Results}

The three groups were comparable regarding the distribution of age, weight, type of surgery, duration of surgery, duration of anesthesia, tympanic temperature immediately before induction and just before extubation, number of patients who received ephedrine, and extubation time after surgery. The vol\% of desflurane was significantly greater and remifentanil dose was significantly lower in group $\mathrm{L}$ than in the other two groups $(\mathrm{p}<0.01)$. The number of patients who received atropine was significantly greater in group $\mathrm{H}$ than group L. PAS within the first hour in the PACU was significantly greater in group $\mathrm{H}$ than in the other two groups $(\mathrm{P}<0.05)$ (Table 2).

Clinically relevant pain including the time to first postopera-

Table 2. Demographic and Anesthetic Data

\begin{tabular}{|c|c|c|c|}
\hline & Group L $(\mathrm{n}=25)$ & Group H $(\mathrm{n}=25)$ & Group HK $(\mathrm{n}=25)$ \\
\hline Age (yr) & $50.8 \pm 6.8$ & $49.3 \pm 5.7$ & $48.9 \pm 6.8$ \\
\hline Weight (kg) & $59.7 \pm 3.4$ & $59.2 \pm 3.3$ & $60.4 \pm 3.6$ \\
\hline \multicolumn{4}{|l|}{ Type of surgery, n (\%) } \\
\hline Ovarian cystectomy & $5(20)$ & $6(24)$ & $5(20)$ \\
\hline Myomecotmy & $8(32)$ & $9(36)$ & $11(44)$ \\
\hline Total hysterectomy & $12(48)$ & $10(40)$ & $9(36)$ \\
\hline Duration of surgery (min) & $154.6 \pm 9.5$ & $152.4 \pm 10.7$ & $150.8 \pm 7.6$ \\
\hline Duration of anesthesia (min) & $167.8 \pm 8.3$ & $168.4 \pm 9.4$ & $166.6 \pm 6.8$ \\
\hline \multicolumn{4}{|l|}{ Tympanic temperature $\left({ }^{\circ} \mathrm{C}\right)$} \\
\hline Immediately before induction & $36.59 \pm 0.12$ & $36.61 \pm 0.12$ & $36.57 \pm 0.12$ \\
\hline Just before extubation & $36.11 \pm 0.32$ & $36.10 \pm 0.31$ & $36.13 \pm 0.29$ \\
\hline Vol\% of desflurane & $6.2 \pm 0.8^{*}$ & $5.2 \pm 0.7$ & $5.0 \pm 0.8$ \\
\hline Remifentanil dose (mg) & $1.00 \pm 0.10^{*}$ & $2.98 \pm 0.20$ & $3.02 \pm 0.18$ \\
\hline Infusion of fluid (ml) & $1296.0 \pm 213.1$ & $1304.0 \pm 238.9$ & $1308.0 \pm 223.5$ \\
\hline Ephedrine, number (\%) of patients & $2(8)$ & $5(20)$ & $4(16)$ \\
\hline $\mathrm{mg}$ & $15.0 \pm 7.1$ & $36.0 \pm 11.4$ & $20.0 \pm 8.2$ \\
\hline Atropine, number (\%) of patients & $3(12)$ & $11(44)^{\dagger}$ & $8(32)$ \\
\hline $\mathrm{mg}$ & $0.5 \pm 0.0$ & $0.6 \pm 0.2$ & $0.6 \pm 0.2$ \\
\hline Extubation time after surgery (min) & $16.4 \pm 3.7$ & $14.0 \pm 3.8$ & $15.0 \pm 3.5$ \\
\hline Postanesthetic shivering in the first hour after surgery in the PACU & $5(20)$ & $14(56)^{*}$ & $6(24)$ \\
\hline
\end{tabular}

Values are expressed as mean \pm SD or number (\%) of patients. Group L: $0.1 \mu \mathrm{g} / \mathrm{kg} / \mathrm{min}$ remifentanil, Group H: 0.3 $\mu \mathrm{g} / \mathrm{kg} / \mathrm{min}, \mathrm{Group} \mathrm{HK:} 0.3 \mu \mathrm{g} / \mathrm{kg} / \mathrm{min}$ remifentanil plus $0.25 \mathrm{mg} / \mathrm{kg}$ ketamine. PACU: postanesthesia care unit. $* \mathrm{P}<0.05$ versus the other 2 groups. ${ }^{\dagger} \mathrm{P}<0.05$ vs group $\mathrm{L}$.

Table 3. Postoperative Clinically Relevant Pain Data

\begin{tabular}{lccc}
\hline & Group L $(\mathrm{n}=25)$ & Group H $(\mathrm{n}=25)$ & Group HK $(\mathrm{n}=25)$ \\
\hline Time to first postoperative analgesic requirement $(\mathrm{min})$ & $36.2 \pm 11.9$ & $32.2 \pm 10.3$ & $36.8 \pm 9.7$ \\
Postoperative pain scores with VAS 1 h after surgery $(\mathrm{mm})$ & $58.0 \pm 12.2$ & $60.1 \pm 20.3$ & $53.6 \pm 12.4$ \\
Analgesic consumption (ketorolac) during the first hour after surgery $(\mathrm{mg})$ & $25.8 \pm 6.9$ & $27.0 \pm 6.1$ & $25.2 \pm 7.1$ \\
Cumulative PCA volume containing morphine for 24 h after surgery $(\mathrm{ml})$ & $58.5 \pm 2.9$ & $60.1 \pm 2.3$ & $58.1 \pm 1.9$ \\
\hline
\end{tabular}

Values are expressed as mean \pm SD. Group L: $0.1 \mu \mathrm{g} / \mathrm{kg} / \mathrm{min}$ remifentanil, Group H: $0.3 \mu \mathrm{g} / \mathrm{kg} / \mathrm{min}$, Group HK: $0.3 \mu \mathrm{g} / \mathrm{kg} / \mathrm{min}$ remifentanil plus 0.25 $\mathrm{mg} / \mathrm{kg}$ ketamine. There were no significant differences between the groups. VAS: visual analog scale, PCA: patient-controlled analgesia. 
tive analgesic requirement, analgesic consumption, and cumulative PCA volume containing morphine was not significantly different among groups (Table 3).

The tactile pain threshold, measured in the peri-incisional area, was significantly reduced $24 \mathrm{~h}$ after surgery compared to preoperative values in all groups. However, the reduction in postoperative tactile pain threshold in group $\mathrm{H}$ was greater than in the other two groups (Fig. 2A). In contrast to the periincisional area, the preoperative and $24 \mathrm{~h}$ postoperative values for tactile pain threshold on the forearm were not significantly different between any of the groups (data not shown). The extent of hyperalgesia $24 \mathrm{~h}$ after surgery was greater in group $\mathrm{H}$ than in the other two groups (Fig. 2B).

PAS was correlated significantly with $\mathrm{OIH}$ including mechanically evoked pain such as postoperative tactile pain threshold $(\mathrm{r}=-0.529, \mathrm{P}=0.01)(\mathrm{r}=-0.458, \mathrm{P}=0.021))$ and the extent of hyperalgesia $(\mathrm{r}=0.537, \mathrm{P}=0.002)(\mathrm{r}=0.384, \mathrm{P}=0.031)$ in groups $\mathrm{H}$ and $\mathrm{HK}$, respectively. Clinically evoked pain such as time to first postoperative analgesic consumption, cumulative PCA volume containing morphine, and analgesic consumption were not correlated significantly with mechanically evoked pain such as tactile pain threshold or extent of hyperalgesia $(\mathrm{P}>0.05)$. PAS was not correlated with clinically relevant pain (Table 4).

\section{Discussion}

Our data showed that high doses of remifentanil caused $\mathrm{OIH}$ due to a reduction in the tactile pain threshold, as demonstrated by increased PAS and the results of quantitative sensory testing (QST), a direct method for the assessment of hyperalgesia. These two effects of high doses of remifentanil were significantly correlated, and both were attenuated by the intraoperative administration of a low dose of ketamine. However, clinically relevant pain indices such as time to first postoperative analgesic requirement, consumption of the analgesic, and cumulative PCA volume containing morphine, which could be considered as indirect manifestations of $\mathrm{OIH}$, were comparable among all groups.

Remifentanil-based anesthesia is used for many types of surgery because it is an ultra-short-acting opioid that can be rapidly titrated for various levels of surgical stimuli. The use of remifentanil assures deep intraoperative analgesia and stable intraoperative hemodynamics, while permitting rapid extubation and recovery at the end of the procedure $[1,14]$. However, it has been reported that high doses of remifentanil induce OIH and PAS, both of which can lead to various consequences such as undesirable oxygen consumption and carbon dioxide production and can cause discomfort to the patient [2-10].
A

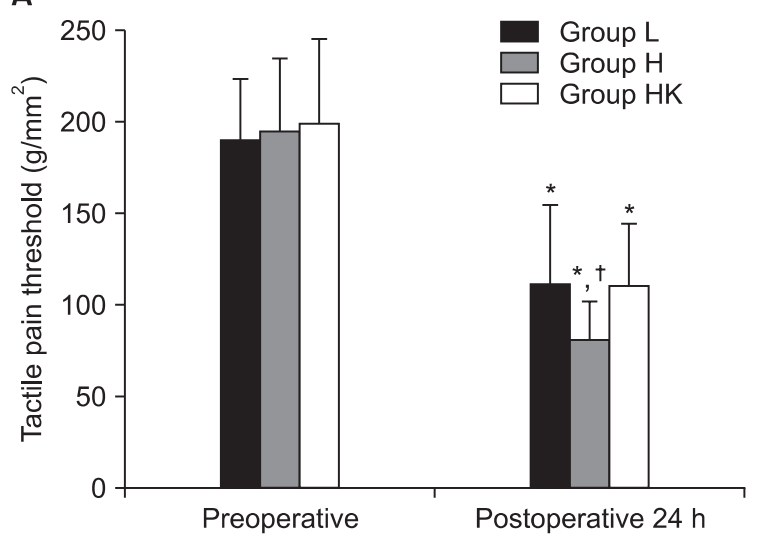

B

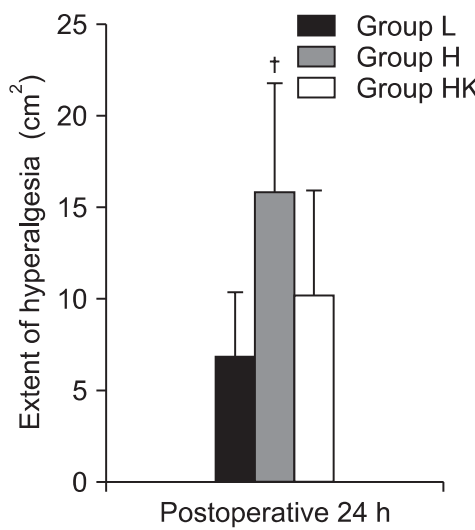

Fig. 2. (A) Mechanically evoked pain tactile pain threshold before and $24 \mathrm{~h}$ after surgery. (B) Extent of hyperalgesia $24 \mathrm{~h}$ after surgery. Group L: $0.1 \mu \mathrm{g} / \mathrm{kg} /$ min remifentanil, Group $\mathrm{H}: 0.3 \mu \mathrm{g} /$ $\mathrm{kg} / \mathrm{min}$, Group HK: $0.3 \mu \mathrm{g} / \mathrm{kg} / \mathrm{min}$ remifentanil plus $0.25 \mathrm{mg} / \mathrm{kg}$ ketamine. $* \mathrm{P}<0.05$ vs preoperative values, ${ }^{\dagger} \mathrm{P}<$ 0.05 vs other two groups.

Table 4. Correlation between Postanesthetic Shivering and OIH including Mechanically Evoked Pain and Clinically Relevant Pain

\begin{tabular}{|c|c|c|c|c|c|c|}
\hline & \multicolumn{2}{|c|}{ Group L } & \multicolumn{2}{|c|}{ Group H } & \multicolumn{2}{|c|}{ Group HK } \\
\hline & $\begin{array}{l}\text { Postoperative } \\
\text { tactile pain } \\
\text { threshold }\end{array}$ & $\begin{array}{c}\text { Extent of } \\
\text { hyperalgesia }\end{array}$ & $\begin{array}{l}\text { Postoperative } \\
\text { tactile pain } \\
\text { threshold }\end{array}$ & $\begin{array}{c}\text { Extent of } \\
\text { hyperalgesia }\end{array}$ & $\begin{array}{l}\text { Postoperative } \\
\text { tactile pain } \\
\text { threshold }\end{array}$ & $\begin{array}{c}\text { Extent of } \\
\text { hyperalgesia }\end{array}$ \\
\hline Postanesthetic shivering & -0.317 & 0.294 & $-0.529 *$ & $0.537 *$ & $0.458^{*}$ & $0.384^{*}$ \\
\hline Time to first postoperative analgesic consumption & 0.153 & -0.239 & 0.170 & -0.081 & -0.315 & 0.141 \\
\hline Cumulative PCA volume containing morphine & -0.175 & 0.120 & -0.150 & 0.062 & 0.252 & -0.195 \\
\hline Analgesic consumption & -0.141 & 0.193 & -0.080 & 0.273 & 0.097 & -0.232 \\
\hline
\end{tabular}

Group L: $0.1 \mu \mathrm{g} / \mathrm{kg} / \mathrm{min}$ remifentanil, Group H: $0.3 \mu \mathrm{g} / \mathrm{kg} / \mathrm{min}$, Group HK: $0.3 \mu \mathrm{g} / \mathrm{kg} / \mathrm{min}$ remifentanil plus $0.25 \mathrm{mg} / \mathrm{kg} \mathrm{ketamine}$. *P $<0.05 \mathrm{versus}$ group L. PCA: patient-controlled analgesia. 
PAS has been attributed to a number of factors including: disinhibited spinal reflexes, pain, decreased sympathetic activity, adrenal suppression, the release of pyrogenic mediators during surgery, the administration of volatile anesthetics, blood loss, the duration of surgery, and thermoregulatory shivering in response to hypothermia [15]. PAS caused by high doses of remifentanil is a common phenomenon; the incidence in group $\mathrm{H}$ was significantly higher (58\%) than that of the other two groups (20-24\%), although tympanic temperature just before extubation was similar in all groups. This indicates that remifentanil-induced PAS is not a phenomenon induced by intraoperative hypothermia. Our results are in agreement with some previous reports that patients treated with high doses of remifentanil were more likely to experience shivering after sudden withdrawal of the drug [8-10].

In the case of $\mathrm{OIH}$, clinically relevant pain that increases postoperative pain scores reduces the time to treatment with opioid analgesics and increases the dose necessary to achieve satisfactory postoperative analgesia. Such measurements represent indirect assessments of OIH. In contrast, mechanically evoked pain such as that modeled in QST with Von Frey filaments decreases detection thresholds and increases mechanical pain sensitivity as well as the wind-up ratio as assessed by pinprick devices and algometers, both of which are methods for the direct assessment of $\mathrm{OIH}$ in patients under opioid-based anesthesia $[3,16]$

As mentioned above, although clinically relevant pain did not differ among groups, mechanically evoked pain including tactile pain threshold and the extent of hyperalgesia induced by QST with Von Frey filaments was significantly higher in group $\mathrm{H}$ than in the other two groups. Our data did not reveal a significant correlation between thresholds and clinically relevant pain. The most likely explanation relates to the type of surgical procedure performed and the use of multimodal analgesic regimens, as well as the timing of drug administration (e.g., preoperative versus postoperative). These findings suggest that a multifactorial modulation of clinically relevant pain. The varying pain severity associated with different surgery types may affect the correlation between clinically relevant pain and mechanically evoked pain [2]. Notably, QST-based efforts to quantify neuroplasticity after surgery can elucidate differences in the mechanisms of perioperative analgesic supplementation not reflected by measurements of clinically relevant pain. In combination with measures of clinically relevant pain such as pain scores or analgesic use, QST measures of surgical neuroplasticity provide insight into the mechanisms involved in the postoperative consequences of nociception. Thus, QST-measured neuroplasticity could provide a basis for the desirable shift from symptom-based to mechanismbased approaches to perioperative pain management [17].

Various studies have shown that volatile anesthetics including desflurane block NMDA receptors $[18,19]$. However, small differences in desflurane concentrations between groups do not explain the exaggerated hyperalgesia observed in patients from group $\mathrm{H}$ treated with high doses of remifentanil. Desflurane attenuates glutamate-induced NMDA receptor responses by only $20 \%$ at $0.5 \mathrm{MAC}$ and $40 \%$ at $1 \mathrm{MAC}$ [18].

Although a number of previous studies have reported that high-dose remifentanil induces OIH and PAS, none has discussed the relationship between these effects. In the present study, PAS correlated significantly with OIH including mechanically evoked pain such as postoperative tactile pain threshold and the extent of hyperalgesia in groups $\mathrm{H}$ and $\mathrm{HK}$, as compared to group L. Nakasuji et al. [8] described the possible mechanisms underlying the shivering induced by the administration of high-dose remifentanil. The authors point out that shivering is a sign of OIH. Remifentanil induced PAS more frequently at high vs. low doses. This result accords with previous reports that high doses of remifentanil cause hyperalgesia $[9,10]$. Both PAS and OIH represent enhanced nociception, which was attenuated in this study by treatment with a low dose of ketamine. In other studies, the PAS or OIH caused by high doses of remifentanil was reduced by intraoperative treatment with magnesium $[20,21]$, which indicates that a common mechanism such as NMDA receptor activation underlies the induction of both effects by high doses of remifentanil. NMDA receptor antagonists appear to modulate central thermoregulatory control mechanisms. The normal functions of these drugs are diverse and the predominant action site of each is difficult to establish, although it is likely that NMDA receptor antagonists modulate thermoregulation at a number of levels. The application of NMDA has been shown to increase the firing rate of neurons in the preoptic-anterior hypothalamus of rats [11].

Our results coincided with those of previous studies showing that remifentanil-based anesthesia is associated with increased pain perception and PAS [8-10]. In one such study, intraoperative tramadol reduced the incidence and extent of PAS without altering pain intensity after surgery under remifentanil-isofluranebased general anesthesia [22]. This suggests that PAS may not be correlated with clinically relevant pain. However, the authors of the study did not investigate the relationship between PAS and mechanically evoked pain; there was no hypothermia causing shivering and no difference between groups in core body temperature at the end of surgery. Taken together, these results suggest that PAS caused by high doses of remifentanil might not be related to perioperative hypothermia or postoperative pain.

Results regarding the effect of a subanesthetic dose of ketamine on hemodynamic stability have been conflicting $[23,24]$. The low dose of ketamine administered in this study was not able to prevent the bradycardia caused by high doses of remifentanil.

One limitation of this study was that although we measured 
PAS $1 \mathrm{~h}$ after surgery, we did not assess tactile pain threshold or the extent of hyperalgesia at the same time point, for fear of contaminating the surgical area. This is not ideal, because the variables measured at different times may not provide accurate evaluations of potential correlations among these variables. This is therefore a possible source of bias that can be investigated in future studies through the inclusion of performance status measures. Further studies are required to elucidate the precise relationship between PAS and OIH including mechanically evoked pain and clinically relevant pain.

In conclusion, $\mathrm{OIH}$ including increased pain perception and PAS caused by high doses of remifentanil are significantly corre- lated. Both effects can be attenuated through the use of NMDA receptor antagonists. This suggests that a common mechanism in part mediated through activation of the central glutamatergic system (e.g., NMDA receptors) underlies the two effects caused by high doses of remifentanil. Further studies are required to investigate the relationship between $\mathrm{OIH}$ and PAS and the use of low-dose ketamine as part of a multimodal approach for treating these effects caused by high doses of remifentanil.

\section{Acknowledgments}

This article was supported by Wonkwang University in 2013.

\section{References}

1. Bürkle H, Dunbar S, Van Aken H. Remifentanil: a novel, short-acting, mu-opioid. Anesth Analg 1996; 83: 646-51.

2. Song JW, Lee YW, Yoon KB, Park SJ, Shim YH. Magnesium sulfate prevents remifentanil-induced postoperative hyperalgesia in patients undergoing thyroidectomy. Anesth Analg 2011; 113: 390-7.

3. Joly V, Richebe P, Guignard B, Fletcher D, Maurette P, Sessler DI, et al. Remifentanil-induced postoperative hyperalgesia and its prevention with small-dose ketamine. Anesthesiology 2005; 103: 147-55.

4. Guignard B, Coste C, Costes H, Sessler DI, Lebrault C, Morris W, et al. Supplementing desflurane-remifentanil anesthesia with small-dose ketamine reduces perioperative opioid analgesic requirements. Anesth Analg 2002; 95: 103-8.

5. Ganne O, Abisseror M, Menault P, Malhière S, Chambost V, Charpiat B, et al. Low-dose ketamine failed to spare morphine after a remifentanil-based anaesthesia for ear, nose and throat surgery. Eur J Anaesthesiol 2005; 22: 426-30.

6. Engelhardt T, Zaarour C, Naser B, Pehora C, de Ruiter J, Howard A, et al. Intraoperative low-dose ketamine does not prevent a remifentanilinduced increase in morphine requirement after pediatric scoliosis surgery. Anesth Analg 2008; 107: 1170-5.

7. Van Elstraete AC, Lebrun T, Sandefo I, Polin B. Ketamine does not decrease postoperative pain after remifentanil-based anaesthesia for tonsillectomy in adults. Acta Anaesthesiol Scand 2004; 48: 756-60.

8. Nakasuji M, Nakamura M, Imanaka N, Tanaka M, Nomura M, Suh SH. Intraoperative high-dose remifentanil increases post-anaesthetic shivering. Br J Anaesth 2010; 105: 162-7.

9. Shin SW, Cho AR, Lee HJ, Kim HJ, Byeon GJ, Yoon JW, et al. Maintenance anaesthetics during remifentanil-based anaesthesia might affect postoperative pain control after breast cancer surgery. Br J Anaesth 2010; 105: 661-7.

10. Möllhoff T, Herregods L, Moerman A, Blake D, MacAdams C, Demeyere R, et al. Comparative efficacy and safety of remifentanil and fentanyl in 'fast track' coronary artery bypass graft surgery: a randomized, double-blind study. Br J Anaesth 2001; 87: 718-26.

11. Dal D, Kose A, Honca M, Akinci SB, Basgul E, Aypar U. Efficacy of prophylactic ketamine in preventing postoperative shivering. Br J Anaesth 2005; 95: 189-92.

12. Kose EA, Dal D, Akinci SB, Saricaoglu F, Aypar U. The efficacy of ketamine for the treatment of postoperative shivering. Anesth Analg 2008; 106: $120-2$.

13. Lee C, Lee HW, Kim JN. Effect of oral pregabalin on opioid-induced hyperalgesia in patients undergoing laparo-endoscopic single-site urologic surgery. Korean J Anesthesiol 2013; 64: 19-24.

14. Scott LJ, Perry CM. Remifentanil: a review of its use during the induction and maintenance of general anaesthesia. Drugs 2005; 65: 1793823.

15. Vanderstappen I, Vandermeersch E, Vanacker B, Mattheussen M, Herijgers P, Van Aken H. The effect of prophylactic clonidine on postoperative shivering. A large prospective double-blind study. Anaesthesia 1996; 51: 351-5.

16. Guignard B, Bossard AE, Coste C, Sessler DI, Lebrault C, Alfonsi P, et al. Acute opioid tolerance: intraoperative remifentanil increases postoperative pain and morphine requirement. Anesthesiology 2000; 93: 409-17.

17. Wilder-Smith OH, Tassonyi E, Crul BJ, Arendt-Nielsen L. Quantitative sensory testing and human surgery: effects of analgesic management on postoperative neuroplasticity. Anesthesiology 2003; 98: 1214-22.

18. Hollmann MW, Liu HT, Hoenemann CW, Liu WH, Durieux ME. Modulation of NMDA receptor function by ketamine and magnesium. Part II: interactions with volatile anesthetics. Anesth Analg 2001; 92: 1182-91.

19. Ogata J, Shiraishi M, Namba T, Smothers CT, Woodward JJ, Harris RA. Effects of anesthetics on mutant N-methyl-D-aspartate receptors expressed in Xenopus oocytes. J Pharmacol Exp Ther 2006; 318: 434-43. 
20. Lee C, Song YK, Jeong HM, Park SN. The effects of magnesium sulfate infiltration on perioperative opioid consumption and opioid-induced hyperalgesia in patients undergoing robot-assisted laparoscopic prostatectomy with remifentanil-based anesthesia. Korean J Anesthesiol 2011; 61: 244-50.

21. Ryu JH, Sohn IS, Do SH. Controlled hypotension for middle ear surgery. a comparison between remifentanil and magnesium sulphate. Br J Anaesth 2009; 103: 490-5.

22. Heid F, Grimm U, Roth W, Piepho T, Kerz T, Jage J. Intraoperative tramadol reduces shivering but not pain after remifentanil-isoflurane general anaesthesia. A placebo-controlled, double-blind trial. Eur J Anaesthesiol 2008; 25: 468-72.

23. DeClue AE, Cohn LA, Lechner ES, Bryan ME, Dodam JR. Effects of subanesthetic doses of ketamine on hemodynamic and immunologic variables in dogs with experimentally induced endotoxemia. Am J Vet Res 2008; 69: 228-32.

24. Kim JM, An YJ, Kim JW. Effect of small-dose ketamine on hemodynamic changes during lower extremity surgery using a tourniquet under general anesthesia. Korean J Anesthesiol 2003; 44: 469-75. 